\title{
Engineering of Corynebacterium glutamicum for growth and production of L-ornithine, L-lysine, and lycopene from hexuronic acids
}

Atika Hadiati, Irene Krahn, Steffen N Lindner and Volker F Wendisch ${ }^{*}$

\begin{abstract}
Background: Second-generation feedstocks such as lignocellulosic hydrolysates are more and more in the focus of sustainable biotechnological processes. Corynebacterium glutamicum, which is used in industrial amino acid production at a million-ton scale, has been engineered towards utilization of alternative carbon sources. As for other microorganisms, the focus has been set on the pentose sugars present in lignocellulosic hydrolysates. Utilization of the hexuronic acids D-galacturonic acid (abundant in pectin-rich waste streams such as peels and pulps) and D-glucuronic acid (a component of the side-chains of plant xylans) for growth and production with C. glutamicum has not yet been studied.

Results: Neither aldohexuronic acid supported growth of C. glutamicum as sole or combined carbon source, although its genome encodes a putative uronate isomerase sharing $28 \%$ identical amino acids with UxaC from Escherichia coli. Heterologous expression of the genes for both uptake and catabolism of D-galacturonic acid and D-glucuronic acid was required to enable growth of C. glutamicum with either aldohexuronic acid as the sole carbon source. When present in mixtures with glucose, the recombinant C. glutamicum strains co-utilized D-galacturonate with glucose and D-glucuronate with glucose, respectively. When transformed with the plasmid for uptake and catabolism of the aldohexuronates, model producer strains were able to grow with and produce from D-galacturonate or D-glucuronate as sole carbon source.

Conclusions: An easily transferable metabolic engineering strategy for access of C. glutamicum to aldohexuronates was developed and applied to growth and production of the amino acids L-lysine and L-ornithine as well as the terpene lycopene from D-galacturonate or D-glucuronate.
\end{abstract}

\section{Background}

Corynebacterium glutamicum is a rod-shaped Grampositive aerobic bacterium, which can be found in soil, sewages, vegetables, and fruits [1]. This bacterium is capable of utilizing various sugars as well as organic acids [2]. Among others, C. glutamicum has the ability to metabolize glucose, fructose, and sucrose as well as lactate, pyruvate, and acetate [2-4]. Characteristic of $C$. glutamicum is the capability of growing on mixtures of different carbon sources with a monoauxic growth $[5,6]$ as opposed to diauxic growth observed for many other microorganisms such as Escherichia coli and Bacillus subtilis [7]. Only a few exceptions have been reported as

\footnotetext{
* Correspondence: volker.wendisch@uni-bielefeld.de

Genetics of Prokaryotes, Center for Biotechnology, Faculty of Biology, Bielefeld University, Universitaetsstraße 25, Bielefeld 33615, Germany
}

in the case of glucose-ethanol or acetate-ethanol mixtures, where preferential substrate utilization was observed [8].

Since its discovery, C. glutamicum has become an indispensable microorganism for the biotechnological industry [9]. From its initial use as a natural L-glutamate producer [10], it is currently used for production of other amino acids such as L-lysine, L-ornithine, L-methionine, and Laspartate [11-14]. However, its importance has further increased as it was for production of of non-natural products [9] such as isobutanol [15], ethanol [16], putrescine $[14,17,18]$, cadaverine [19], carotenoids and terpenoids [20-25], and xylitol [26].

Recently, efforts with C. glutamicum have shifted from optimizing production processes to also include access to alternative carbon sources. As yet, feed in the industry 
relies mainly on glucose and fructose [8], which also have competing uses in the food industry. So far, alternative carbon source utilization in C. glutamicum has been successfully established, among others, for xylose [27,28], galactose [29], arabinose [14,30], glucosamine [31], Nacetyl-glucosamine [32], and glycerol [33]. Plant cell wall materials such as lignocellulose and pectin are promising alternatives as carbon source. These materials are readily and abundantly available as agricultural waste or forestry residues [34]. Among the sugar constituents of plant cell wall are the hexuronic acids D-galacturonate and D- glucuronate found in pectin. These acidic sugars are naturally consumed by most plant pathogenic bacteria such as Erwinia carotovora, Pseudomonas syringae, and Agrobacterium tumefaciens, but also by E. coli.

There are three pathways for utilization of hexuronic acids, namely via isomerization, oxidation, and reduction [35]. The isomerization pathway in E. coli consists of seven reactions, which yield the central intermediates Dglyceraldehyde-3-phosphate and pyruvate (Figure 1). Both $u x a C-u x a A$ and $u x u A-u x u B$ are located within operons. However, these operons and the remaining genes

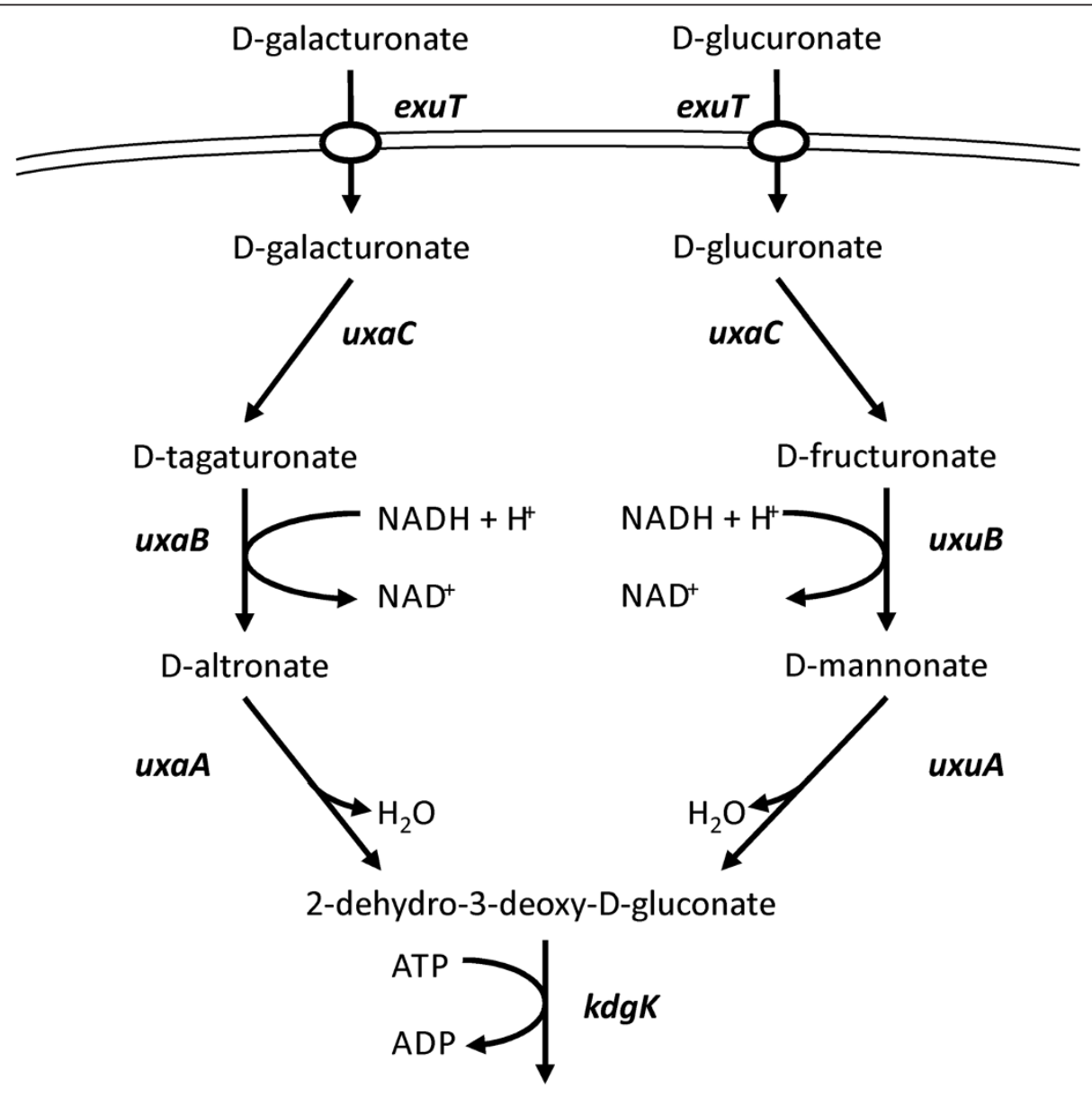

2-dehydro-3-deoxy-D-gluconate 6-phosphate

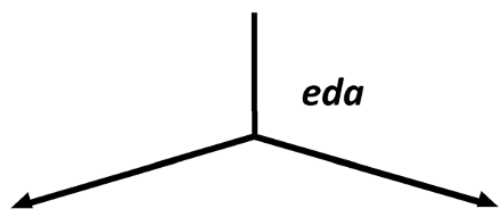

pyruvate

D-glyceraldehyde 3-phosphate

Figure 1 Schematic representation of the D-galacturonate and D-glucuronate catabolic pathways of $E$. coli. Gene names are given adjacent to the reactions: eda, 2-keto-3-deoxygluconate-6-phosphate aldolase; exuT, uptake system for hexuronic acids; kdgK, 2-keto-3-

deoxygluconokinase; $u x a A$, altronate dehydratase; $u x a B$, altronate oxidoreductase; $u x a C$, uronate isomerase; $u x u A$, mannonate dehydratase; $u x u B$, mannonate oxidoreductase. 
are not clustered but spread across the genome of E. coli. The genes $k d g K$ and $e d a$ belong to the modified EntnerDoudoroff pathway, which is present in many Gramnegative bacteria, pseudomonads, and Archaea [36]. Bioinformatic analysis revealed an $u x a C$ ortholog in the genome of C. glutamicum with $28 \%$ protein similarity to that of E. coli. However, homologs of $u x a B, u x u A, u x u B$, $k d g K$, and eda appear to be absent. Therefore, in this work, C. glutamicum was engineered for the uptake and utilization of D-galacturonate and D-glucuronate as alternative carbon sources. The potential of this synthetic pathway was then analyzed with respect to the production of the amino acids L-lysine and L-ornithine as well as the carotenoid lycopene.

\section{Methods}

Microorganisms, plasmids, and cultivation conditions

The wild-type strain C. glutamicum ATCC 13032 used in this study was obtained from the American Type Culture Collection (ATCC). Other strains include C. glutamicum ORN1 [14], C. glutamicum DM1933 [37], and C. glutamicum $\triangle$ crtYEB [23] that are derived from the wild-type strain (Table 1). The hexuronic acid utilization and transporter genes originated from E. coli MG1655, whereas the strain E. coli DH5a [38] was used for plasmid construction. Both E. coli strains were obtained from the Coli Genetic Stock Center (CGSC). For cultivations, the Luria broth (LB) complex medium and CGXII minimal medium [39] were used and contained glucose,

Table 1 Strains, plasmids, and oligonucleotides used in this study

\begin{tabular}{|c|c|c|}
\hline Name & Relevant genotype/information & Reference \\
\hline \multicolumn{3}{|l|}{ E. coli strain } \\
\hline $\mathrm{DH} 5 \mathrm{a}$ & (p80lacZAM15) $\Delta$ (lacZYA-argF)U169 deoR recA1 endA1 hsdR17(rK-, mK-) supE44 thi1 gyrA96 relA1 & [38] \\
\hline \multicolumn{3}{|c|}{ C. glutamicum strains } \\
\hline WT & Wild-type strain ATCC 13032, auxotrophic for biotin & [40] \\
\hline ORN1 & $\begin{array}{l}\text { In-frame deletion of } \arg R \text { and } \arg F \text {, L-ornithine overproducing strain derived } \\
\text { from C. glutamicum WT } \\
\text { ATCC 13032, auxotrophic for L-arginine }\end{array}$ & [14] \\
\hline DM1933 & $\begin{array}{l}\Delta p c k \text { deletion mutant of } C \text {. glutamicum WT also carrying the chromosomal changes } \\
\text { pyc(P458S), hom (V59A), two copies of lys C(T3111), two copies of asd, two copies of } \\
\operatorname{dapA} \text {, two copies of dapB, two copies of } d d h \text {, two copies of lysA, two copies of lysE }\end{array}$ & [37] \\
\hline$\triangle c r t Y E b$ & $\operatorname{crt}_{\mathrm{Y}} Y_{f} E b$ deletion mutant of C. glutamicum MB001 & [23] \\
\hline \multicolumn{3}{|l|}{ Plasmids } \\
\hline pEKEX3 & Spec $^{R} ;$ E. coli/C. glutamicum shuttle vector for regulated gene expression $\left(P_{t a c}\right.$ lacl $^{q}$, pBL1 oriV $\left.{ }_{C g}\right)$ & [41] \\
\hline pHexA & $\begin{array}{l}\text { pEKEx3 derivative for IPTG-inducible expression of } u \times a C A B, u \times u A B, k d g K \text {, and eda from } \\
\text { E. coli containing artificial ribosome binding sites each }\end{array}$ & This work \\
\hline pWWEx1 & $\mathrm{Km}^{\mathrm{R}}$; E. coli/C. glutamicum shuttle vector for regulated gene expression ( $P_{\text {tac }} \mid$ lacla, pCG1 oriV $\left.{ }_{C g}\right)$ & {$[42]$} \\
\hline pWWEX1-exuT & $\begin{array}{l}\text { pWWEx1 derivative for IPTG-inducible expression of exuT from E. coli containing artificial } \\
\text { ribosome binding site }\end{array}$ & This work \\
\hline \multicolumn{3}{|l|}{ Primers } \\
\hline Gla & GCAGGTCGACTCTAGAGGATCCCCGAAAGGAGGCCCTTCAGATGACTCCGTTATGACTGAAGATTTC & \\
\hline G1b & GTACTAGCTAATGCAATCAGTGATGTTATAGCGTTACGCCGCTTITG & \\
\hline G2d & CATCACTGATTGCATTAGCTAGTACGAAAGGAGGCCCTTCAGATGAAAACACTAAATCGTCGCGAT & \\
\hline G2C & GCTAATGGTGCTATCTGGTACGATCTTAGCACAACGGACGTACAG & \\
\hline G3d & GATCGTACCAGATAGCACCATTAGCGAAAGGAGGCCCTTCAGATGGAACAGACCTGGCGC & \\
\hline G3f & GCAGGTCGACTCTAGAGGATCCCCATGGAACAGACCTGGCGCTGGTACGGCC & \\
\hline $\mathrm{G} 3 \mathrm{C}$ & CGTTCTAGTTACTTTGGAACGTACCTTACAGCGCAGCCACACA & \\
\hline G4d & GGTACGTTCCAAAGTAACTAGAACGGAAAGGAGGCCCTTCAGATGTCCAAAAAGATTGCCGTGAT & \\
\hline G4C & GTCAATCCATGGCATTCTAGCCAAGTTACGCTGGCATCGCCTC & \\
\hline $\mathrm{G} 5 \mathrm{~d}$ & CTTGGCTAGAATGCCATGGATTGACGAAAGGAGGCCCTTCAGATGAAAAACTGGAAAACAAGTGCAG & \\
\hline $\mathrm{G} 5 \mathrm{C}$ & GCCAGTGAATTCGAGCTCGGTACCCTTACAGCTTAGCGCCTTCTACAG & \\
\hline ExuT-fw & CTGCAGGTCGACTCTAGAGGAAAGGAGGCCCTTCAGA & \\
\hline ExuT-rv & CGGTACCCGGGGATCTTAATGTTGCGGTGCGGGATC & \\
\hline
\end{tabular}


D-galacturonate, or D-glucuronate in concentrations as indicated in the 'Results' section. Kanamycin $\left(25 \mu \mathrm{g} \mathrm{ml}^{-1}\right)$, spectinomycin $\left(100 \mu \mathrm{g} \mathrm{ml} \mathrm{m}^{-1}\right)$, and/or isopropyl- $\beta$-D-thiogalactopyranoside (IPTG; $20 \mu \mathrm{M}$ ) were added to the medium when necessary. Cultivations were carried out in 50-ml cultures in 500-ml baffled Erlenmeyer flasks on a rotary shaker at $120 \mathrm{rpm}$ and $30^{\circ} \mathrm{C}$ for C. glutamicum or $37^{\circ} \mathrm{C}$ for $\mathrm{E}$. coli. In both cases, the growth in liquid cultures was followed by measuring the optical density at $600 \mathrm{~nm}\left(\mathrm{OD}_{600}\right)$.

\section{DNA preparation, modification, and transformation}

Standard procedures were used for plasmid and chromosomal DNA isolation, molecular cloning, and transformation of E. coli. Plasmid isolation for C. glutamicum was carried out as described previously [43]. Transformation of C. glutamicum by electroporation was carried out as described [39]. PCR experiments were carried out in a thermocycler (Analytik Jena AG, Jena, Germany) with KOD Hot Start DNA Polymerase (Novagen, Merck KGaA, Darmstadt, Germany) and with oligonucleotides obtained from Eurofins MWG Operon (Eurofins Genomics, Ebersberg, Germany) as listed in Table 2. Restriction enzymes, T4 DNA Ligase, and alkaline phosphatase were obtained from New England BioLabs, Inc. (Ipswich, MA, USA) and used according to the manufacturer's protocol.

\section{Construction of plasmids and strains}

For the construction of pHexA, the $u x a C A$ and $u x u A B$ operons as well as genes $u x a B, k d g K$, and eda were amplified by PCR from E. coli MG1655. The uxaCA operon was amplified with primers $\mathrm{Gla}+\mathrm{G} 1 \mathrm{~b}$ resulting in a 2,981-bp product, whereas the $u x u A B$ operon was amplified with primers $\mathrm{G} 3 \mathrm{f}+\mathrm{G} 3 \mathrm{c}$ resulting in a 2,775-bp product. Gene $u x a B$ was amplified with primers $\mathrm{G} 2 \mathrm{~d}+$ $\mathrm{G} 2 \mathrm{c}$, gene $k d g K$ with primers $\mathrm{G} 4 \mathrm{~d}+\mathrm{G} 4 \mathrm{c}$, and eda was amplified with primers G5d + G5c resulting in 1,519-, 997-, and 709-bp PCR products, respectively. Through these primers, appropriate linker sequences and a ribosomal binding site (RBS) sequence were attached to each gene or operon to facilitate the Gibson assembly [44]. The genetic load was first divided due to the insert size. Therefore, genes $u x u A B, k d g K$, and $e d a$ were cloned into the SmaI-digested pEKEx3 resulting in pEKEx3-uxuAB$k d g K$-eda, designated as pAB5. The insert of pAB5 was amplified via PCR with primers G3d and G5d with a 4481bp PCR product. The pAB5 amplicon, $u x a B$, and $u x a C A$ were then used for Gibson assembly into the SmaIdigested pEKEx3 and yielded the final vector $\mathrm{pHexA}$. The aldohexuronate transporter gene exuT was amplified via PCR with primers ExuT-fw and ExuT-rv from E. coli MG1655 and used for Gibson assembly into the BamHIdigested pVWEx1. The plasmid inserts were verified by sequencing (Sequencing Core Facility CeBiTec, Bielefeld,
Germany), and the plasmids were used to transform C. glutamicum ATCC 13032.

\section{DNA microarray analysis}

C. glutamicum ATCC 13032 was cultivated in CGXII medium with $50 \mathrm{mM}$ D-galacturonate plus $50 \mathrm{mM}$ glucose, $50 \mathrm{mM}$ D-glucuronate plus $50 \mathrm{mM}$ glucose, or $50 \mathrm{mM}$ glucose as carbon source. Exponentially growing cells were harvested after $4 \mathrm{~h}$. RNA isolation, cDNA synthesis, and microarray hybridization were performed according to previous protocols [45]. Microarray images were analyzed with ImaGene software (BioDiscovery, Inc., Hawthorne, CA, USA), whereas the EMMA platform was used for data evaluation.

\section{Quantification of amino acids and carbohydrates}

To evaluate the amino acid and carbohydrate production, culture samples were taken and centrifuged $(13.000 \times g$, $10 \mathrm{~min}$ ), and the supernatant analyzed by high-pressure liquid chromatography (HPLC, 1200 series, Agilent Technologies Inc., Santa Clara, CA, USA) as described previously $[14,21]$.

\section{Computational analysis}

Protein alignments were carried out via the BLASTP algorithm [46] of NCBI (Bethesda, MD, USA). The GenBank accession number for the annotated genome sequence of C. glutamicum ATCC 13032 and E. coli MG1655 is NC_006958 [47] and NC_000913 [48], respectively.

\section{Results}

\section{Response of C. glutamicum WT to D-galacturonate and D-glucuronate}

D-galacturonate and D-glucuronate were tested as potential carbon sources of C. glutamicum. However, although its genome encodes a putative uronate isomerase sharing $28 \%$ identical amino acids with UxaC from $E$. coli, both compounds did not support growth as sole carbon sources at $50 \mathrm{mM}$ (data not shown). When present in addition to $50 \mathrm{mM}$ glucose, C. glutamicum wild type (WT) grew to comparable maximal $\mathrm{OD}_{600}$ values of about 18 irrespective of the presence or absence of Dgalacturonate or D-glucuronate (data not shown). Surprisingly, the presence of $50 \mathrm{mM}$ D-galacturonate in minimal medium with $50 \mathrm{mM}$ glucose accelerated growth slightly $\left(0.24 \mathrm{~h}^{-1}\right.$ as compared to $\left.0.17 \mathrm{~h}^{-1}\right)$, while the addition of $50 \mathrm{mM}$ D-glucuronate to glucose minimal medium slowed growth of WT $\left(0.13 \mathrm{~h}^{-1}\right)$. These observations prompted us to carry out DNA microarray experiments to study global gene expression under these conditions. Genes differentially expressed in cells growing exponentially with $50 \mathrm{mM}$ D-galacturonate plus $50 \mathrm{mM}$ glucose, $50 \mathrm{mM}$ $\mathrm{D}$-glucuronate plus $50 \mathrm{mM}$ glucose, and $50 \mathrm{mM}$ glucose alone are listed in Table 2. As expected, the presence of 
Table 2 Gene expression analysis of C. glutamicum WT in CGXII minimal medium with $50 \mathrm{mM}$ glucose ${ }^{\mathrm{a}}$

\begin{tabular}{llll}
\hline & Gene ID & Description & M \\
\hline $\begin{array}{l}\text { Differentially expressed } \\
\text { genes in the presence } \\
\text { of D-glucuronate }\end{array}$ & & Idh, L-lactate dehydrogenase & 1.7 \\
& &
\end{tabular}

of D-glucuronate

\begin{tabular}{|c|c|c|c|}
\hline & cg3303 & $\begin{array}{l}\text { Transcriptional regulator PadR } \\
\text { family }\end{array}$ & 1.6 \\
\hline & cg0580 & Hypothetical protein & 1.5 \\
\hline & $\operatorname{cg} 2789$ & $\begin{array}{l}n r d H \text {, glutaredoxin-like } \\
\text { protein } \mathrm{NrdH}\end{array}$ & -1.5 \\
\hline & $\operatorname{cg} 2182$ & $\begin{array}{l}\text { ABC-type peptide transport } \\
\text { system, permease } \\
\text { component }\end{array}$ & -1.5 \\
\hline & cg3300 & Cation transport ATPase & -1.5 \\
\hline & cg2477 & Hypothetical protein & -1.6 \\
\hline & cg1809 & $\begin{array}{l}\text { DNA-directed RNA } \\
\text { polymerase subunit omega }\end{array}$ & -1.7 \\
\hline & cg0935 & Hypothetical protein & -1.8 \\
\hline & cg1286 & Hypothetical protein & -1.8 \\
\hline $\begin{array}{l}\text { Differentially expressed } \\
\text { genes in the presence }\end{array}$ & cg2313 & $\begin{array}{l}\text { idhA3, myo-inositol } \\
\text { 2-dehydrogenase }\end{array}$ & 2.0 \\
\hline & $\operatorname{cg} 1118$ & $\begin{array}{l}\text { Pyrimidine reductase, } \\
\text { riboflavin biosynthesis }\end{array}$ & 1.9 \\
\hline & cg0687 & $\begin{array}{l}\text { gcp, putative O- } \\
\text { sialoglycoprotein } \\
\text { endopeptidase }\end{array}$ & 1.9 \\
\hline & $\operatorname{cg} 1116$ & $t d c B$, threonine dehydratase & 1.9 \\
\hline & $\operatorname{cg} 1784$ & $\begin{array}{l}\text { ocd, putative ornithine } \\
\text { cyclodeaminase }\end{array}$ & 1.9 \\
\hline & cg3096 & ald, aldehyde dehydrogenase & 1.9 \\
\hline & cg0792 & $\begin{array}{l}\text { Thioredoxin domain- } \\
\text { containing protein }\end{array}$ & 1.8 \\
\hline & cg0682 & ATPase or kinase & 1.7 \\
\hline & cg1003 & $\begin{array}{l}\text { fthC, 5-formyltetrahydrofolate } \\
\text { cycloligase }\end{array}$ & 1.7 \\
\hline & cg1134 & $\begin{array}{l}\text { pabAB, para-aminobenzoate } \\
\text { synthase components I and II }\end{array}$ & 1.7 \\
\hline & $\operatorname{cg} 1438$ & $\begin{array}{l}\text { ABC-type transport system, } \\
\text { ATPase component } \\
\text { (C-terminal fragment) }\end{array}$ & 1.7 \\
\hline & cg2430 & Hypothetical protein & 1.7 \\
\hline & cg1560 & $\begin{array}{l}\text { uvrA, excinuclease ATPase } \\
\text { subunit }\end{array}$ & 1.7 \\
\hline & cg1014 & $\begin{array}{l}\text { pmt, protein O- } \\
\text { mannosyltransferase }\end{array}$ & 1.6 \\
\hline & $\operatorname{cg} 1668$ & Putative membrane protein & 1.6 \\
\hline & cg2625 & $\begin{array}{l}\text { pcaF, } \beta \text {-ketoadipyl COA } \\
\text { thiolase }\end{array}$ & 1.6 \\
\hline & cg2094 & Hypothetical protein & 1.6 \\
\hline & $\operatorname{cg} 1241$ & Hypothetical protein & 1.5 \\
\hline & cg1876 & Glycosyltransferase & 1.5 \\
\hline
\end{tabular}

Table 2 Gene expression analysis of C. glutamicum WT in CGXII minimal medium with $50 \mathrm{mM}$ glucose ${ }^{\mathrm{a}}$ (Continued)

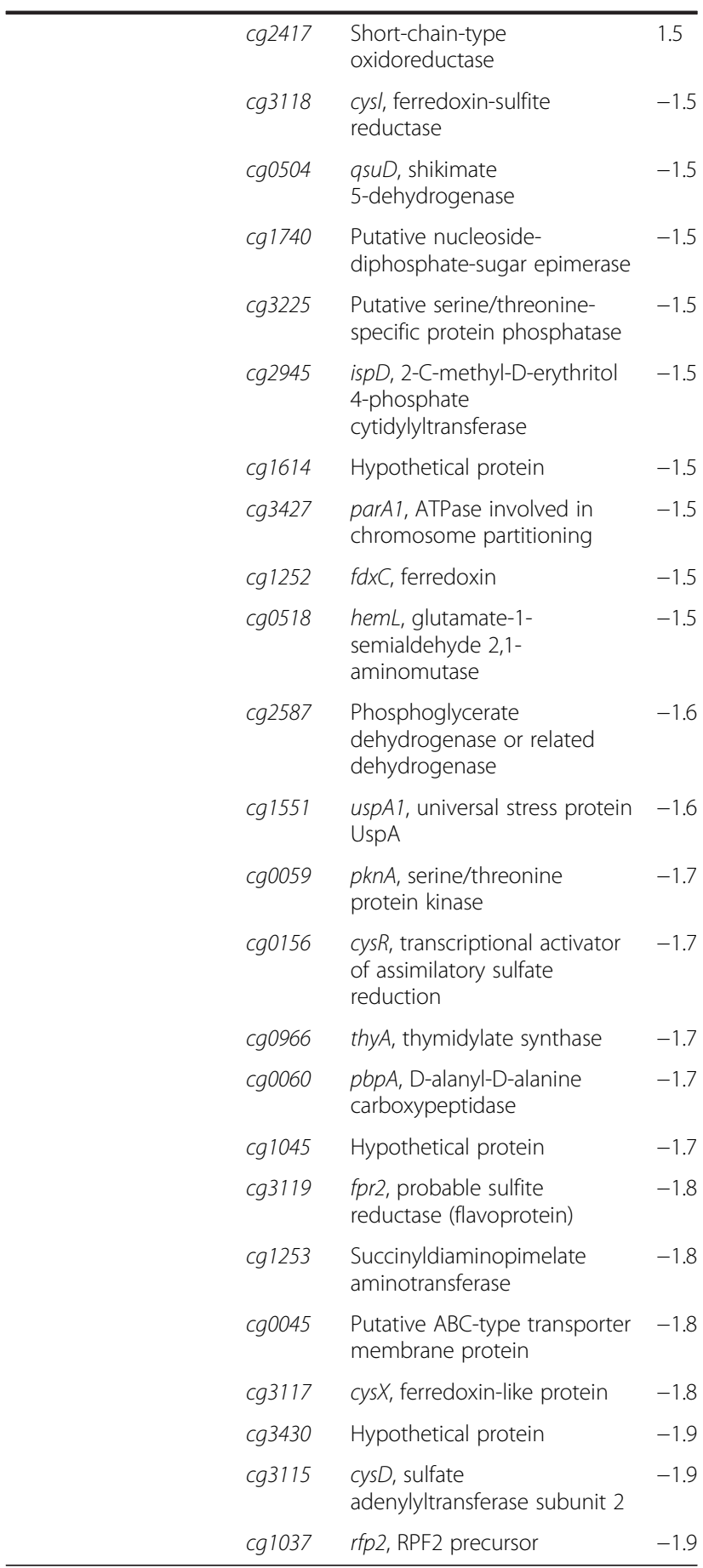

${ }^{a}$ Statistical evaluation was carried out with the $t$-test, where $p \leq 0.05$, log expression ratio $M \geq 1.5$ or $\leq-1.5$, and signal intensity $A \geq 10$. Values are averages of three independent cultivations.

D-galacturonate elicited different gene expression changes than D-glucuronate. Since neither D-galacturonate nor D-glucuronate was metabolized, these gene expression changes are likely due to regulatory or secondary effects. To elicit such regulatory changes, transport of minute 
amounts of D-galacturonic or D-glucuronic acid might be sufficient.

Increased expression of fermentative lactate dehydrogenase gene $l d h A$ in the presence of $\mathrm{D}$-glucuronate might have slowed growth with glucose since lactate is known to accumulate transiently and since high $l d h A$ levels have been implied to slow growth of C. glutamicum with sugars [49]. Furthermore, expression of the gene for subunit omega of RNA polymerase was reduced, thus transcription might have been negatively affected more in general. The gene expression changes due to the presence of $\mathrm{D}$ galacturonate did not allow deriving a potential explanation for faster growth with glucose. However, decreased expression of cg1551 encoding putative universal stress protein UspA is in line with faster growth of C. glutamicum in the presence of D-galacturonate.

\section{Expression of genes for catabolism of D-galacturonate and D-glucuronate in C. glutamicum WT}

Plasmid pHexA was constructed for heterologous expression of the $E$. coli genes for degradation of D-galacturonate and D-glucuronate to the glycolytic intermediates pyruvate and glyceraldehyde-3-phosphate. To this end, the operons $u x a C A$ and $u x u A B$ as well as genes $u x a B, k d g K$, and $e d a$ were cloned with attached RBS sequences as synthetic operon into IPTG-inducible gene expression vector pEKEx3. The resulting plasmid pHexA was used to transform $C$. glutamicum WT. However, the transformants were unable to grow with either D-galacturonate or D-glucuronate as sole carbon sources (data not shown).

\section{Co-expression of exuT from E. coli was required for uptake of hexuronic acids}

Since endowing C. glutamicum with D-galacturonate or Dglucuronate catabolism proved insufficient for utilization of these substrates, the gene for the respective uptake system exuT was co-expressed from a compatible plasmid. In preliminary experiments, C. glutamicum WT (pHexA)(pVWEx1-exuT) did indeed grow with either $\mathrm{D}$-galacturonate or D-glucuronate as sole carbon source, however, very slowly. Based on the assumption that overproduction of transmembrane protein ExuT perturbed growth, the concentration of the inducer IPTG was titrated. Moreover, it was required to pre-cultivate the strain in minimal medium with a mixture of $50 \mathrm{mM}$ glucose and $50 \mathrm{mM}$ of either D-galacturonate or D-glucuronate as carbon source. In the main culture with $50 \mathrm{mM}$ of either Dgalacturonate or D-glucuronate, no growth was observed for C. glutamicum WT(pHexA)(pVWEx1). By contrast, C. glutamicum WT(pHexA)(pVWEx1-exuT) was able to grow with $\mathrm{D}$-galacturonate and $\mathrm{D}$-glucuronate, respectively, with growth rates of $0.06 \pm 0.01$ and $0.05 \pm 0.01 \mathrm{~h}^{-1}$, respectively (data not shown). Thus, these results revealed that C. glutamicum WT lacks the ability for uptake and catabolism of hexuronic acids and that heterologous expression of the genes from $E$. coli for uptake and catabolism of hexuronic acids enabled access of C. glutamicum to $\mathrm{D}$-galacturonate and D-glucuronate as growth substrates.

\section{Co-utilization of hexuronic acids with glucose expression by C. glutamicum WT(pHexA)(pVWEx1)}

A hallmark of C. glutamicum is its ability to co-utilize various carbon sources when these are added as carbon source mixtures. To assay if hexuronic acids are utilized simultaneously with glucose, the preferred carbon source of C. glutamicum, the growth and substrate consumption of C. glutamicum WT(pHexA)(pVWEx1) in minimal medium containing either $100 \mathrm{mM}$ D-galacturonate plus $100 \mathrm{mM}$ glucose or $100 \mathrm{mM} \mathrm{D}$-glucuronate plus $100 \mathrm{mM}$ glucose were determined (Figure 2). In minimal medium with the mixture of $\mathrm{D}$-galacturonate plus glucose, C. glutamicum WT(pHexA)(pVWEx1) grew with a growth rate of $0.25 \pm 0.02 \mathrm{~h}^{-1}$ and co-utilized glucose with D-galacturonate (Figure 2). Specific uptake rates of $28 \pm 3$ and $39 \pm 4 \mathrm{nmol}(\mathrm{mg} \text { cell dry weight }(\mathrm{CDW}))^{-1}$ $\mathrm{min}^{-1}$ were derived for utilization of $\mathrm{D}$-galacturonate and glucose, respectively. In minimal medium with a blend of $100 \mathrm{mM}$ D-glucuronate plus $100 \mathrm{mM}$ glucose, both carbon sources were utilized simultaneously and support a growth rate of $0.25 \pm 0.02 \mathrm{~h}^{-1}$ for C. glutamicum WT(pHexA)(pVWEx1) (Figure 2). The specific uptake rates were $21 \pm 2 \mathrm{nmol}(\mathrm{mg} C D W)^{-1} \mathrm{~min}^{-1}$ for glucose and $18 \pm 2 \mathrm{nmol}(\mathrm{mg} \mathrm{CDW})^{-1} \mathrm{~min}^{-1}$ for D-glucuronate.

\section{Production of L-lysine, L-ornithine, and lycopene by recombinant $C$. glutamicum strains from D-galacturonate and D-glucuronate}

The natural substrate spectrum of C. glutamicum has been broadened to realize a flexible feedstock concept for production processes using this bacterium [27-33]. To test if recombinant C. glutamicum strains engineered to accept $\mathrm{D}$-galacturonate and $\mathrm{D}$-glucuronate as growth substrates are able to produce, e.g., amino acids from these substrates, model L-lysine, L-ornithine, and lycopene producer strains were transformed with plasmids pHexA and pVWEx1-exuT. These strains were cultivated in CGXII minimal medium with $20 \mu \mathrm{M}$ IPTG and either $100 \mathrm{mM}$ D-galacturonate or $100 \mathrm{mM}$ D-glucuronate as sole carbon source.

The lysine-producing strain C. glutamicum DM1933 carries a number of chromosomal changes known to be beneficial for L-lysine production [37]. DM1933(pHexA) (pVWEX1-exuT) hardly grew with either D-galacturonate or D-glucuronate (Table 3). However, DM1933(pHexA) (pVWEX1-exuT) produced $6.5 \pm 0.2 \mathrm{mM}$ L-lysine from $100 \mathrm{mM}$ D-galacturonate and $9.3 \pm 1.1 \mathrm{mM} \mathrm{L}$-lysine from 100 mM D-glucuronate (Table 3). 

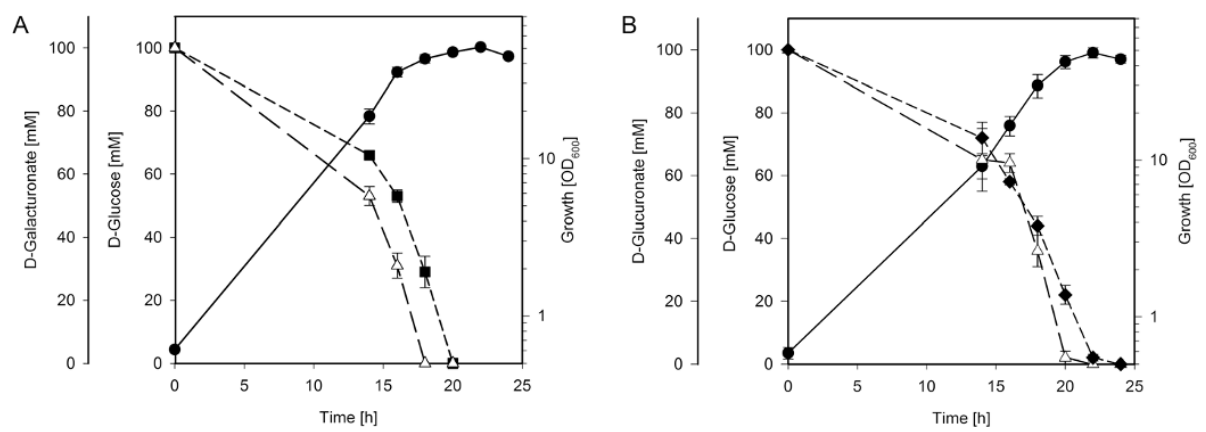

Figure 2 Growth of $C$. glutamicum strains WT(pHexA)(pVWEx1-exuT) with blends of D-glucose and D-galacturonate (A) or D-glucose and D-glucuronate (B). Residual concentrations of D-galacturonate (closed squares), D-glucuronate (closed diamonds), and D-glucose (open triangles) and OD600 values (closed circles) are given as means and standard deviations of triplicate cultivations in CGXII minimal medium, $\mathrm{pH}$ 6.3, with $20 \mu \mathrm{M} \mathrm{IPTG}$, and either a mixture of $100 \mathrm{mM}$ D-galacturonate and $100 \mathrm{mM}$ D-glucose (A) or a mixture of $100 \mathrm{mM}$ D-glucuronate plus 100 mM D-glucose (B) as carbon sources.

Lycopene accumulates in C. glutamicum $\triangle$ crtYEb due to disruption of the pathway for biosynthesis of the endogenous carotenoid decaprenoxanthin [20]. C. glutamicum $\triangle c r t Y E b(\mathrm{pHexA})(\mathrm{pVWEX1-exuT)}$ grew with $\mathrm{D}$-galacturonate $\left(0.02 \pm 0.01 \mathrm{~h}^{-1}\right)$ and D-glucuronate $\left(0.04 \pm 0.01 \mathrm{~h}^{-1}\right)$, respectively, as sole carbon source (Table 3). The strain produced $0.7 \pm 0.1 \mathrm{mg}(\mathrm{g} \mathrm{CDW})^{-1}$

Table 3 Batch fermentations of L-lysine-, L-ornithine-, and lycopene-producing strains in minimal medium with D-galacturonate or D-glucuronate

\begin{tabular}{|c|c|c|c|}
\hline & & D-galacturonate & D-glucuronat \\
\hline \multicolumn{4}{|c|}{$\begin{array}{l}\text { L-lysine by DM1933(pHexA) } \\
\text { (pVWEx1-exuT) }\end{array}$} \\
\hline & $C_{\text {Lys }}(m M)$ & $6.5 \pm 0.2$ & $9.3 \pm 1.1$ \\
\hline & $\mu\left(h^{-1}\right)$ & $0.01 \pm 0.01$ & $0.02 \pm 0.01$ \\
\hline & $\begin{array}{l}Y_{p / s} \\
\left(g_{\text {Lys }} g_{\text {substrate }}{ }^{-1}\right)\end{array}$ & $0.04 \pm 0.01$ & $0.07 \pm 0.01$ \\
\hline \multicolumn{4}{|c|}{$\begin{array}{l}\text { Lycopene by } \triangle c r t Y E b(p H e x A) \\
\text { (pVWEx1-exuT) }\end{array}$} \\
\hline & $C_{\text {Lyc }}(\mathrm{mg} / \mathrm{g})$ & $0.7 \pm 0.1$ & $0.8 \pm 0.3$ \\
\hline & $\mu\left(h^{-1}\right)$ & $0.02 \pm 0.01$ & $0.04 \pm 0.01$ \\
\hline & $\begin{array}{l}Y_{p / s} \\
\left(g_{\text {Lyc }} g_{\text {substrate }}{ }^{-1}\right)\end{array}$ & $0.09 \pm 0.01$ & $0.08 \pm 0.02$ \\
\hline \multicolumn{4}{|c|}{$\begin{array}{l}\text { L-ornithine by ORN1(pHexA) } \\
\text { (pVWEx1-exuT) }\end{array}$} \\
\hline \multirow{3}{*}{$\begin{array}{l}\text { With } 0.75 \mathrm{mM} \\
\text { L-arginine }\end{array}$} & $C_{\mathrm{Orn}}(\mathrm{mM})$ & $2.4 \pm 0.2$ & $<0.5$ \\
\hline & $\mu\left(h^{-1}\right)$ & $0.03 \pm 0.01$ & $0.03 \pm 0.01$ \\
\hline & $\begin{array}{l}Y_{p / s} \\
\left.\text { (gorn } g_{\text {substrate }}{ }^{-1}\right)\end{array}$ & $0.01 \pm 0.01$ & $<0.01$ \\
\hline \multirow{3}{*}{$\begin{array}{l}\text { With } 0.125 \mathrm{mM} \\
\text { L-arginine }\end{array}$} & $C_{\text {Orn }}(m M)$ & $1.7 \pm 0.1$ & $0.6 \pm 0.2$ \\
\hline & $\mu\left(h^{-1}\right)$ & $0.04 \pm 0.01$ & $0.03 \pm 0.01$ \\
\hline & $\begin{array}{l}Y_{p / s} \\
\text { (Gorn }_{\text {substrate }}{ }^{-1} \text { ) }\end{array}$ & $0.01 \pm 0.01$ & $<0.01$ \\
\hline
\end{tabular}

$\overline{\text { CGXII minimal medium was used with } 100 \mathrm{mM} \text { of the indicated carbon source. }}$ lycopene in minimal medium with $\mathrm{D}$-galacturonate and $0.8 \pm 0.3 \mathrm{mg}(\mathrm{g} \mathrm{CDW})^{-1}$ lycopene with $\mathrm{D}$-glucuronate (Table 3).

C. glutamicum ORN1 is an L-arginine auxotrophic derivative of C. glutamicum WT that secretes L-ornithine due to deletions of the L-ornithine carbamoyltransferase gene $\arg F$ and the $\mathrm{L}$-arginine biosynthesis repressor gene $\operatorname{argR}$ [14]. When supplemented with either $0.75 \mathrm{mM}$ or $0.125 \mathrm{mM}$ L-arginine, C. glutamicum ORN1(pHexA) (pVWEX1-exuT) grew in D-galacturonate and Dglucuronate minimal medium with growth rates of about $0.04 \pm 0.01 \mathrm{~h}^{-1}$ (Table 3). However, L-ornithine accumulated only to low concentrations corresponding to yields of about 1 to $2 \mathrm{~mol} \%$ (Table 3 ).

\section{Discussion}

C. glutamicum WT is not capable of utilizing hexuronic acids. Heterologous expression of gene for catabolism and uptake of the hexuronic acid pathway from E. coli in C. glutamicum enabled utilization of both D-galacturonate and D-glucuronate as sole carbon sources in minimal medium. Moreover, both hexuronates were co-utilized with glucose by the recombinant C. glutamicum strains developed here. Simultaneous utilization of several carbon sources as required for efficient utilization of substrate mixtures such as in lignocellulosic hydrolysates is a hallmark of C. glutamicum $[6,8]$ and also pertains to coutilization of non-native substrates by the respective recombinants [14,27,28,30-33].

Notably, the aldohexuronate transporter ExuT was strictly required, indicating that $C$. glutamicum lacks the capacity to import sugar acids. ExuT belongs to the major facilitator superfamily (MFS) class of transporters, more specifically to the anion:cation symporter (ACS) family [50]. This class of symporters transfers organic/inorganic anions while simultaneously co-transporting $\mathrm{H}^{+} / \mathrm{Na}^{+}$, respectively. ExuT has not been reported to transport other 
substrates than the aldohexuronic acids. Inspection of the genome of C. glutamicum WT showed only one protein with $22 \%$ similarity to ExuT, namely putative lincomycin resistance protein LMRB (YP 226924.1). Engineering $C$. glutamicum for growth with other non-native carbon sources does not necessarily require heterologous expression of a gene encoding a transport system. Introduction of catabolic genes for conversion of glycerol, arabinose, and xylose was sufficient to enable utilization of these carbon sources by these recombinant $C$. glutamicum strains, while additional introduction of the respective uptake system accelerated carbon source utilization $[27,28,33,51,52]$. Transport engineering was not required for the amino sugar glucosamine, which is a substrate of the endogenous glucose-specific PTS [31], whereas the amino sugar Nacetylglucosamine could only be utilized if NagE from the related Corynebacterium glycinophilum was introduced [32]. In the latter case as well as in the present study, it was necessary to adjust the concentration of the inducer IPTG. It is often observed that too high levels of a transmembrane protein such as a transport protein results in growth perturbation [53,54]. In addition, expression levels of several genes of a pathway may need to be tuned to avoid accumulation of potentially inhibitory intermediates as demonstrated for C. glutamicum engineered for decaprenoxanthin overproduction [23].

It is not known if the recombinant $C$. glutamicum strain WT(pHexA)(pVWEX1-exuT) would be able to grow with sugar acids related to the aldohexuronates Dgalacturonate and D-glucuronate since ExuT is specific for aldohexuronate uptake. In E. coli, the intermediate of aldohexuronate catabolism D-fructuronate serves as carbon source and its utilization requires uptake by GntP [55]. C. glutamicum possesses GntP for gluconate uptake [56], but it is unknown whether GntP from C. glutamicum accepts D-fructuronate or the related intermediates of aldohexuronate catabolism D-tagaturonate, D-altronate, or D-mannonate as substrates. Recently, it was shown that E. coli may grow with L-galactonate and L-gulonate as sole carbon sources with L-galactonate-5-dehydrogenase YjjN being required for their conversion to $\mathrm{D}$-tagaturonate and D-fructuronate, respectively [57]. Under osmotic stress conditions, E. coli may use a different pathway, i.e., 5-keto 4-deoxyuronate isomerase $\mathrm{KduI}$ and 2-deoxy-D gluconate 3-dehydrogenase $\mathrm{KduD}$ may compensate for reduced levels of UxaC, UxaB, and UxuB under osmotic stress conditions [58]. Since ExuT from E. coli was required for aldohexuronate utilization by recombinant C. glutamicum, it is likely that introduction of the respective uptake systems for the related sugar acids described above is a prerequisite for their use as carbon sources.

Degradation of aldohexuronate to pyruvate yields one mole of ATP per mole of aldohexuronate by substratelevel phosphorylation as compared to two moles of ATP per glucose in the Embden-Meyerhof-Parnas (EMP) pathway of glycolysis as present in C. glutamicum. In the EMP pathway of glycolysis, two moles of nicotinamide adenine dinucleotide (NADH) are generated from glucose, while no net formation of $\mathrm{NADH}$ occurs in aldohexuronate conversion to pyruvate (Figure 1). The maximal $\mathrm{OD}_{600}$ values reflecting the maximal biomass concentration with $50 \mathrm{mM}$ $\mathrm{D}$-galacturonate consequently were lower $\left(\mathrm{OD}_{600}\right.$ of about 6.5) than with $50 \mathrm{mM}$ glucose $\left(\mathrm{OD}_{600}\right.$ of about 18). The maximal $\mathrm{OD}_{600}$ (about 4.5) with $50 \mathrm{mM}$ D-glucuronate was even lower (data not shown). The reduced biomass yields for aerobic growth with the aldohexuronates can be explained at least in part by their lower ATP yields as compared to glucose catabolism. The growth rates in minimal medium with D-galacturonate $\left(0.06 \mathrm{~h}^{-1}\right)$ and D-glucuronate $\left(0.05 \mathrm{~h}^{-1}\right)$, respectively, obtained with C. glutamicum WT(pHexA)(pVWEx1-exuT) are five to six times lower than with glucose. Aldohexuronate utilization may be accelerated, e.g., by improving heterologous gene expression or by using catabolic enzymes of other microorganisms as in the case of xylose [28]. Instability of the plasmids pHexA and pVWEX1-exuT were not observed in the experiments described here; however, it might be possible that plasmid instability poses a challenge when using these strains in large fermentation vessels.

The low biomass yields and slow growth rates observed with C. glutamicum WT(pHexA)(pVWEx1-exuT) were also found when the respective plasmids were transformed into model producer strains. The product yields observed were low, e.g., about 6 to $9 \mathrm{~mol} \%$ for L-lysine (Table 3). Thus, the aldohexuronates are not good substrates for growth and production by C. glutamicum. However, endowing C. glutamicum strains with aldohexuronate catabolism may be a requirement for complete and efficient utilization of second-generation feedstocks ensuring that not only the major sugar fractions are converted to value-added products.

\section{Conclusions}

Access of C. glutamicum to the aldohexuronates Dgalacturonate and D-glucuronate was established by heterologous expression of genes for catabolism and uptake of the aldohexuronates from E. coli in C. glutamicum. This metabolic engineering strategy could be applied to Dgalacturonate- or D-glucuronate-based growth and production of the amino acids L-lysine and L-ornithine as well as the terpene lycopene.

Competing interests

The authors declare that they have no competing interests.

\section{Authors' contributions}

$\mathrm{AH}$ planned and performed the experiments, analyzed the data, and drafted the paper. IK performed the experiments and analyzed the data. SNL planned the experiments and analyzed the data. VFW designed and 
coordinated the study, analyzed the data, and wrote the paper. All authors read and approved the final manuscript.

\section{Acknowledgements}

We thank Petra Peters-Wendisch for help with artwork. Work in the lab of the authors was funded in part by grants 0315589G from BMBF in the CRP 'Corynebacterium: improving flexibility and fitness for industrial production'.

\section{Received: 25 September 2014 Accepted: 5 November 2014 Published online: 15 November 2014}

\section{References}

1. Eggeling L, Bott M (2005) Handbook of Corynebacterium glutamicum. CRC, Boca Raton

2. Blombach B, Seibold GM (2010) Carbohydrate metabolism in Corynebacterium glutamicum and applications for the metabolic engineering of L-lysine production strains. Appl Microbiol Biotechnol 86(5):1313-1322, doi:10.1007/s00253-010-2537-z

3. Cocaign M, Monnet C, Lindley ND (1993) Batch kinetics of Corynebacterium glutamicum during growth on various carbon sources: use of substrate mixtures to localise metabolic bottlenecks. Appl Microbiol Biotechnol 40:526-530

4. Dominguez H, Cocaign-Bousquet M, Lindley ND (1997) Simultaneous consumption of glucose and fructose from sugar mixtures during batch growth of Corynebacterium glutamicum. Appl Microbiol Biotechnol 47(5):600-603

5. Dominguez H, Nezondet C, Lindley ND, Cocaign M (1993) Modified carbon flux during oxygen limited growth of Corynebacterium glutamicum and the consequences for amino acid overproduction. Biotech Lett 15:449-454

6. Wendisch VF, de Graaf AA, Sahm H, Eikmanns BJ (2000) Quantitative determination of metabolic fluxes during coutilization of two carbon sources: comparative analyses with Corynebacterium glutamicum during growth on acetate and/or glucose. J Bacteriol 182(11):3088-3096

7. Monod J (1949) The growth of bacterial cultures. Ann Rev Microbiol 3:371-394

8. Zahoor A, Lindner SN, Wendisch VF (2012) Metabolic engineering of Corynebacterium glutamicum aimed at alternative carbon sources and new products. Comput Struct Biotechnol J 3:e201210004, doi:10.5936/ csbj.201210004

9. Wendisch VF (2014) Microbial production of amino acids and derived chemicals: synthetic biology approaches to strain development. Curr Opin Biotechnol 30C:51-58, doi:10.1016/j.copbio.2014.05.004

10. Ikeda M (2003) Amino acid production processes. Adv Biochem Eng Biotechnol 79:1-35

11. Wendisch VF (2007) Amino acid biosynthesis - pathways, regulation and metabolic engineering. Springer, Heidelberg

12. Hermann $T$ (2003) Industrial production of amino acids by coryneform bacteria. J Biotechnol 104(1-3):155-172

13. Leuchtenberger W, Huthmacher K, Drauz K (2005) Biotechnological production of amino acids and derivatives: current status and prospects. Appl Microbiol Biotechnol 69(1):1-8

14. Schneider J, Niermann K, Wendisch VF (2011) Production of the amino acids L-glutamate, L-lysine, L-ornithine and L-arginine from arabinose by recombinant Corynebacterium glutamicum. J Biotechnol 154(2-3):191-198, doi:10.1016/j.jbiotec.2010.07.009

15. Blombach B, Riester T, Wieschalka S, Ziert C, Youn JW, Wendisch VF, Eikmanns BJ (2011) Corynebacterium glutamicum tailored for efficient isobutanol production. Appl Environ Microbiol 77(10):3300-3310, doi:10.1128/AEM. 02972-10

16. Inui M, Kawaguchi H, Murakami S, Vertes AA, Yukawa H (2004) Metabolic engineering of Corynebacterium glutamicum for fuel ethanol production under oxygen-deprivation conditions. J Mol Microbiol Biotechnol 8(4):243-254, doi:10.1159/000086705

17. Schneider J, Wendisch VF (2010) Putrescine production by engineered Corynebacterium glutamicum. Appl Microbiol Biotechnol 88(4):859-868, doi:10.1007/s00253-010-2778-x

18. Schneider J, Eberhardt D, Wendisch VF (2012) Improving putrescine production by Corynebacterium glutamicum by fine-tuning ornithine transcarbamoylase activity using a plasmid addiction system. Appl Microbiol Biotechnol 95(1):169-178, doi:10.1007/s00253-012-3956-9

19. Mimitsuka T, Sawai H, Hatsu M, Yamada K (2007) Metabolic engineering of Corynebacterium glutamicum for cadaverine fermentation. Biosci Biotechnol Biochem 71(9):2130-2135, doi:10.1271/bbb.60699
20. Heider SA, Peters-Wendisch $P$, Netzer $R$, Stafnes M, Brautaset $T$, Wendisch VF (2014) Production and glucosylation of C50 and C 40 carotenoids by metabolically engineered Corynebacterium glutamicum. Appl Microbiol Biotechnol 98(3):1223-1235, doi:10.1007/s00253-013-5359-y

21. Heider SA, Peters-Wendisch P, Wendisch VF (2012) Carotenoid biosynthesis and overproduction in Corynebacterium glutamicum. BMC Microbiol 12:198, doi:10.1186/1471-2180-12-198

22. Heider SA, Peters-Wendisch P, Wendisch VF, Beekwilder J, Brautaset T (2014) Metabolic engineering for the microbial production of carotenoids and related products with a focus on the rare $\mathrm{C} 50$ carotenoids. Appl Microbiol Biotechnol 98(10):4355-4368, doi:10.1007/s00253-014-5693-8

23. Heider SA, Wolf N, Hofemeier A, Peters-Wendisch P, Wendisch VF (2014) Optimization of the IPP precursor supply for the production of lycopene, decaprenoxanthin and astaxanthin by Corynebacterium glutamicum. Front Bioeng Biotechnol 2:28, doi:10.3389/fbioe.2014.00028

24. Frohwitter J, Heider SA, Peters-Wendisch P, Beekwilder J, Wendisch VF (2014) Production of the sesquiterpene (+)-valencene by metabolically engineered Corynebacterium glutamicum. J Biotechnol, doi:10.1016/j. jbiotec.2014.05.032

25. Kang MK, Eom JH, Kim Y, Um Y, Woo HM (2014) Biosynthesis of pinene from glucose using metabolically-engineered Corynebacterium glutamicum. Biotechnol Lett 36(10):2069-2077, doi:10.1007/s10529-014-1578-2

26. Sasaki M, Jojima T, Inui M, Yukawa H (2009) Xylitol production by recombinant Corynebacterium glutamicum under oxygen deprivation. Appl Microbiol Biotechnol 86:1057-1066, doi:10.1007/s00253-009-2372-2

27. Gopinath V, Meiswinkel TM, Wendisch VF, Nampoothiri KM (2011) Amino acid production from rice straw and wheat bran hydrolysates by recombinant pentose-utilizing Corynebacterium glutamicum. Appl Microbiol Biotechnol 92(5):985-996, doi:10.1007/s00253-011-3478-x

28. Meiswinkel TM, Gopinath V, Lindner SN, Nampoothiri KM, Wendisch VF (2013) Accelerated pentose utilization by Corynebacterium glutamicum for accelerated production of lysine, glutamate, ornithine and putrescine. Microb Biotechnol 6(2):131-140, doi:10.1111/1751-7915.12001

29. Barrett E, Stanton C, Zelder O, Fitzgerald G, Ross RP (2004) Heterologous expression of lactose- and galactose-utilizing pathways from lactic acid bacteria in Corynebacterium glutamicum for production of lysine in whey. Appl Environ Microbiol 70(5):2861-2866

30. Kawaguchi H, Sasaki M, Vertes AA, Inui M, Yukawa H (2009) Identification and functional analysis of the gene cluster for L-arabinose utilization in Corynebacterium glutamicum. Appl Environ Microbiol 75(11):3419-3429, doi:10.1128/AEM.02912-08

31. Uhde A, Youn JW, Maeda T, Clermont L, Matano C, Kramer R, Wendisch VF, Seibold GM, Marin K (2013) Glucosamine as carbon source for amino acid-producing Corynebacterium glutamicum. Appl Microbiol Biotechnol 97 (4):1679-1687, doi:10.1007/s00253-012-4313-8

32. Matano C, Uhde A, Youn JW, Maeda T, Clermont L, Marin K, Kramer R, Wendisch VF, Seibold GM (2014) Engineering of Corynebacterium glutamicum for growth and L-lysine and lycopene production from N-acetyl-glucosamine. Appl Microbiol Biotechnol 98(12):5633-5643, doi:10.1007/s00253-014-5676-9

33. Rittmann D, Lindner SN, Wendisch VF (2008) Engineering of a glycerol utilization pathway for amino acid production by Corynebacterium glutamicum. Appl Environ Microbiol 74(20):6216-6222, doi:10.1128/AEM. 00963-08

34. Zaldivar J, Nielsen J, Olsson L (2001) Fuel ethanol production from lignocellulose: a challenge for metabolic engineering and process integration. Appl Microbiol Biotechnol 56(1-2):17-34

35. Boer H, Maaheimo H, Koivula A, Penttila M, Richard P (2010) Identification in Agrobacterium tumefaciens of the D-galacturonic acid dehydrogenase gene. Appl Microbiol Biotechnol 86(3):901-909, doi:10.1007/s00253-009-2333-9

36. Conway T (1992) The Entner-Doudoroff pathway: history, physiology and molecular biology. FEMS Microbiol Rev 9(1):1-27

37. Blombach B, Hans S, Bathe B, Eikmanns BJ (2009) Acetohydroxyacid synthase, a novel target for improvement of L-lysine production by Corynebacterium glutamicum. Appl Environ Microbiol 75(2):419-427, doi:10.1128/AEM. 01844-08

38. Hanahan D (1983) Studies on transformation of Escherichia coli with plasmids. J Mol Biol 166(4):557-580

39. Eggeling L, Reyes O (2005) Experiments. In: Eggeling L, Bott M (eds) Handbook of Corynebacterium glutamicum. CRC, Boca Raton, pp 3535-3566

40. Abe S, Takayarna K, Kinoshita S (1967) Taxonomical studies on glutamic acid-producing bacteria. J Gen Appl Microbiol 13:279-301 
41. Stansen C, Uy D, Delaunay S, Eggeling L, Goergen JL, Wendisch VF (2005) Characterization of a Corynebacterium glutamicum lactate utilization operon induced during temperature-triggered glutamate production. Appl Environ Microbiol 71(10):5920-5928, doi:10.1128/AEM. 71.10.5920-5928.2005

42. Peters-Wendisch PG, Schiel B, Wendisch VF, Katsoulidis E, Mockel B, Sahm H, Eikmanns BJ (2001) Pyruvate carboxylase is a major bottleneck for glutamate and lysine production by Corynebacterium glutamicum. J Mol Microbiol Biotechnol 3(2):295-300

43. Eikmanns BJ, Thum-Schmitz N, Eggeling L, Lüdtke KU, Sahm H (1994) Nucleotide sequence, expression and transcriptional analysis of the Corynebacterium glutamicum gltA gene encoding citrate synthase. Microbiology 140(Pt 8):1817-1828

44. Gibson DG, Young L, Chuang RY, Venter JC, Hutchison CA, 3rd, Smith HO (2009) Enzymatic assembly of DNA molecules up to several hundred kilobases. Nat Methods 6(5):343-345, doi:10.1038/nmeth.1318

45. Wendisch VF (2003) Genome-wide expression analysis in Corynebacterium glutamicum using DNA microarrays. J Biotechnol 104(1-3):273-285

46. Altschul SF1, Gish W, Miller W, Myers EW, Lipman DJ (1990) Basic local alignment search tool. J Mol Biol 215:403-410

47. Kalinowski J, Bathe B, Bartels D, Bischoff N, Bott M, Burkovski A, Dusch N, Eggeling L, Eikmanns BJ, Gaigalat L, Goesmann A, Hartmann M, Huthmacher K, Kramer R, Linke B, McHardy AC, Meyer F, Mockel B, Pfefferle W, Puhler A, Rey DA, Ruckert C, Rupp O, Sahm H, Wendisch VF, Wiegrabe I, Tauch A (2003) The complete Corynebacterium glutamicum ATCC 13032 genome sequence and its impact on the production of L-aspartate-derived amino acids and vitamins. J Biotechnol 104(1-3):5-25

48. Blattner FR, Plunkett G 3rd, Bloch CA, Perna NT, Burland V, Riley M, Collado-Vides J, Glasner JD, Rode CK, Mayhew GF, Gregor J, Davis NW, Kirkpatrick HA, Goeden MA, Rose DJ, Mau B, Shao Y (1997) The complete genome sequence of Escherichia coli K-12. Science 277(5331):1453-1474

49. Engels V, Lindner SN, Wendisch VF (2008) The global repressor SugR controls expression of genes of glycolysis and of the L-lactate dehydrogenase LdhA in Corynebacterium glutamicum. J Bacteriol 190(24):8033-8044, doi:10.1128/JB.00705-08

50. Pao SS, Paulsen IT, Saier MH Jr (1998) Major facilitator superfamily. Microbiol Mol Biol Rev 62(1):1-34

51. Meiswinkel TM, Rittmann D, Lindner SN, Wendisch VF (2013) Crude glycerolbased production of amino acids and putrescine by Corynebacterium glutamicum. Bioresour Technol 145:254-258, doi:10.1016/j. biortech.2013.02.053

52. Sasaki M, Jojima T, Kawaguchi H, Inui M, Yukawa H (2009) Engineering of pentose transport in Corynebacterium glutamicum to improve simultaneous utilization of mixed sugars. Appl Microbiol Biotechnol 85(1):105-115, doi:10.1007/s00253-009-2065-x

53. Youn JW, Jolkver E, Kramer R, Marin K, Wendisch VF (2008) Identification and characterization of the dicarboxylate uptake system DccT in Corynebacterium glutamicum. J Bacteriol 190(19):6458-6466, doi:10.1128/JB.00780-08

54. Youn JW, Jolkver E, Kramer R, Marin K, Wendisch VF (2009) Characterization of the dicarboxylate transporter DctA in Corynebacterium glutamicum. J Bacteriol 191(17):5480-5488, doi:10.1128/JB.00640-09

55. Bates Utz C, Nguyen AB, Smalley DJ, Anderson AB, Conway T (2004) GntP is the Escherichia coli fructuronic acid transporter and belongs to the UxuR regulon. J Bacteriol 186(22):7690-7696, doi:10.1128/JB.186.22.7690-7696.2004

56. Frunzke J, Engels V, Hasenbein S, Gatgens C, Bott M (2008) Co-ordinated regulation of gluconate catabolism and glucose uptake in Corynebacterium glutamicum by two functionally equivalent transcriptional regulators, GntR1 and GntR2. Mol Microbiol 67(2):305-322, doi:10.1111/.j.1365-2958.2007.06020.x

57. Kuivanen J, Richard P (2014) The yjjN of E. coli codes for an L-galactonate dehydrogenase and can be used for quantification of $\mathrm{L}$-galactonate and $\mathrm{L}$-gulonate. Appl Biochem Biotechnol 173(7):1829-1835, doi:10.1007/s12010-014-0969-0

58. Rothe M, Alpert C, Loh G, Blaut M (2013) Novel insights into E. coli's hexuronate metabolism: Kdul facilitates the conversion of galacturonate and glucuronate under osmotic stress conditions. PLoS One 8(2):e56906, doi:10.1371/journal.pone.0056906

doi:10.1186/s40643-014-0025-5

Cite this article as: Hadiati et al: Engineering of Corynebacterium glutamicum for growth and production of L-ornithine, L-lysine, and lycopene from hexuronic acids. Bioresources and Bioprocessing 2014 1:25.

\section{Submit your manuscript to a SpringerOpen ${ }^{\circ}$ journal and benefit from:}

- Convenient online submission

- Rigorous peer review

- Immediate publication on acceptance

- Open access: articles freely available online

- High visibility within the field

- Retaining the copyright to your article

Submit your next manuscript at $>$ springeropen.com 